\title{
Mapping Robots to Therapy and Educational Objectives for Children with Autism Spectrum Disorder
}

\author{
Claire A. G. J. Huijnen ${ }^{1,3} \cdot$ Monique A. S. Lexis ${ }^{1} \cdot$ Rianne Jansens $^{1,2} \cdot$ Luc P. de Witte $^{1,3}$
}

Published online: 24 February 2016

(c) The Author(s) 2016. This article is published with open access at Springerlink.com

\begin{abstract}
The aim of this study was to increase knowledge on therapy and educational objectives professionals work on with children with autism spectrum disorder (ASD) and to identify corresponding state of the art robots. Focus group sessions $(\mathrm{n}=9)$ with ASD professionals $(\mathrm{n}=53)$ from nine organisations were carried out to create an objectives overview, followed by a systematic literature study to identify state of the art robots matching these objectives. Professionals identified many ASD objectives $(\mathrm{n}=74)$ in 9 different domains. State of the art robots addressed 24 of these objectives in 8 domains. Robots can potentially be applied to a large scope of objectives for children with ASD. This objectives overview functions as a base to guide development of robot interventions for these children.
\end{abstract}

Keywords Autism spectrum disorder (ASD) - Children · Therapy and education objectives $\cdot$ Robots

Claire A. G. J. Huijnen

claire.huijnen@zuyd.nl

1 Research Centre Technology in Care, Zuyd University of Applied Sciences, Henri Dunantstraat 2, 6419 PB Heerlen, The Netherlands

2 Occupational Therapy Department, Zuyd University of Applied Sciences, Heerlen, The Netherlands

3 Faculty of Health, Medicine and Life Sciences, CAPHRI School for Public Health and Primary Care, Maastricht University, Maastricht, The Netherlands

\section{Introduction}

An increasing number of children across the globe are being diagnosed with autism spectrum disorder (ASD) (Blaxill 2004; Olds et al. 2013; Scassellati 2005; Wong et al. 2014). From recent studies, a best prevalence estimate of children with ASD of $0.66 \%$ or 1 child in 152 children can be made although also higher numbers have been reported (Volkmar et al. 2014). The Diagnostic and Statistical Manual of Mental Disorders (DSM-V) describes the diagnostic criteria for ASD (American Psychiatric Association 2013). According to the DSM-V, people with ASD often experience persistent problems in social communication and social interaction across multiple contexts on the one hand, and show restricted, repetitive patterns of behaviour, interests, or activities on the other hand. Clinically significant impairments in social, occupational, or other important areas of functioning are apparent (American Psychiatric Association 2013). The symptoms manifest on a continuum, a spectrum, with some individuals showing mild symptoms and others having more severe symptoms and challenges in daily life, and demanding more support (Neurodevelopmental and Group 2012). Together with these differences in severity of symptoms, large variations in symptoms cause ASD to be a highly heterogeneous disorder.

Children with ASD benefit from early and ongoing intervention that is tailored to their specific needs (Volkmar et al. 2014). Even if children reveal progress in some areas during their school time after receiving care, for example in language proficiency, many other areas nevertheless require extensive support, for example in social interaction and communication skills (Volkmar et al. 2014). Most children with ASD continue to have ASD as an adult and continue to experience challenges related to independent 
living, employment, social relationships and mental health (Myers and Johnson 2007).

Ongoing research has proven the acceptance and efficiency of technology as a support tool for the therapy and education of individuals with ASD and the people who support them on a daily basis (Aresti-Bartolome and Garcia-Zapirain 2014; Boucenna et al. 2014; Goldsmith and LeBlanc 2004; Grynszpan et al. 2014; Lee and Hyun 2015)

Theory of Mind (ToM) refers to the ability to understand one's own and other people's beliefs, intentions, desires, imagination, and emotions (Baron-Cohen et al. 1985). Often children with autism have difficulties in ToM. Technologies might provide tools to address these impairments because they can create situations or environments in which children can practice and learn in a safer (e.g. more predictable) and more pleasant manner than when they would practice this (only) with a person. Technologies can deliberately focus on targeting the strengths and weaknesses of the disorder by creating controlled environments that might reduce the anxiety that "real" social situations may cause for children with ASD (Aresti-Bartolome and Garcia-Zapirain 2014). More specifically, socially interactive robots or robot assisted therapy are suggested to be of potential added value in the therapy of children with autism (Cabibihan et al. 2013). Boucenna et al. (2014) suggest a number of reasons for this expected beneficial effect; it might be easier for children with ASD to interact with robots than with humans. Robots (less complex, more predictable, and simpler) can also provide novel sensory stimuli and tend to occupy a special niche between inanimate toys (which do not trigger novel social behaviours for these children) and humans (which can be a source of confusion or even distress for them) (Scassellati et al. 2012). In other words, robots enable embodied interactions that are appealing for children with ASD. Possibly robots can simultaneously provide humanlike social cues (e.g. waving, smiling) while maintaining object-like simplicity (e.g. in a consistent manner, limited facial expressions) (Thill et al. 2013). Thill et al. (2013) summarized a number of advantages of using robots for children with ASD: robots can be applied in a controlled manner so that only relevant information is presented minimising the risk of creating stressful and complex situations, robots are better in endless repetition than people, and variations can be made in a conscious (and safe) manner.

Scassellati et al. (2012) report encouraging effects such as increased engagement, increased levels of attention and novel social behaviours, for example joint attention and imitation, when the children interact with robots.

Earlier work (Cabibihan et al. 2013) presented a compilation of robots that have been studied for children with autism and distinguished a number of benefits and roles that robots could have. These roles range from a "friendly playmate", a "behaviour eliciting agent", a "social mediator" or a "social actor" to a "personal therapist" (Diehl et al. 2012). A review of the clinical use of robots for individuals with ASDs identified four categories for the roles for interactive robots in clinical applications: the response of individuals (often children) with ASD to robots or robot-like behaviour in comparison to human behaviour, the use of robots to elicit behaviours, the use of robots to model, teach or practice a skill and the use of robots to provide feedback on performance (Aresti-Bartolome and Garcia-Zapirain 2014).

Although most of these studies yielded positive effects using robots for children with autism (e.g. show an increase in desired target behaviours, increased response times, show appreciation/interest for robot interaction), not all children would benefit from (the same) robotic support (Diehl et al. 2012) or would perform better with a human counterpart compared with a robot (Duquette et al. 2008). Mixed results and variability in the nature of the affective response (e.g. positive or negative reaction towards the robot) are also reported; children are not likely to always react positively to the robot (Feil-Seifer and Mataric 2011). This, again, underlines the need for personalised and tailored interventions for this heterogeneous target group.

With respect to teachers' acceptance on the use of robots in education, one study found that pre-school and elementary teachers accepted a human-like robot to serve as an interactive tool in the teaching process (Fridin and Belokopytov 2014). Other findings regarding attitudes towards the use of robots in (psycho)therapy or education for children show that people, overall, tend to have positive attitudes, considering them as useful and potentially effective tools in psychological treatments or interventions (Costescu and David 2014; Fridin and Belokopytov 2014; Oros et al. 2014).

Despite this work with promising results, the actual current state of application of robots for children with autism in care/therapy and education practices is still relatively in an early stage. More research is needed to understand the actual clinical effects and added value in therapy and education (Diehl et al. 2012). Moreover, it would be interesting to better understand in what areas robots can actually add value to the functioning of children with autism, and how this relates to the "International Classification of Functioning, Disability and Health" (ICF) (World Health Organization 2007). The ICF for children and youth (ICF-CY) provides a classification for health and health-related domains and addresses all aspects of functioning specifically for children and youth.

A critical review by Diehl et al. (2012) concluded that many of these studies are explorative in nature and have 
methodological limitations and do not necessarily focus on the clinical application of the technology but more on the development of the technology (Diehl et al. 2012). The exploration of robot-based autism intervention has often been directed at clinical or therapy settings and less on educational settings in which children might also benefit from the use of robots in the curriculum (Shamsuddin et al. 2015).

Furthermore, although research has proved the potential added value of different kinds of technologies for children with autism, however, often these tools currently lack the ability to personalise to a specific person's needs (American Psychiatric Association 2013). Especially for such a diverse and heterogeneous target group as children with autism, it is extremely important that interventions address challenges in different dimensions and a personalised offering is possible (Volkmar et al. 2014). Technologies, including robots might be able to fulfil this requirement as they allow for personalisation and customisation to the individual's specific needs.

Actual clinical application of robot technology in practice requires the expertise of both technology developers as well as experts in the area of children with ASD. Although public opinion and press devote more and more attention to the use of robots in the therapy or education for children with ASD, scientific peer reviewed publications of systematic clinical effectiveness of the actual implementation of robot based interventions for children with ASD are still scarce.

For robots to be of clinical added value, obviously, teachers and/or care professionals have to accept, adopt and embed these robots in their daily practices. To be used, interventions need to meet the needs of children as well as the needs and practices of these professionals. This is a rather challenging task. For robot developers, it can be quite hard to understand and relate to the needs of this heterogeneous target group and therefore difficult to develop appropriate robot systems to be used as part of interventions. For professionals working with children with ASD on the other hand, the world of social robots seems quite invisible, far away or unreachable. Yet, in order for robot assisted therapy to bring added value to the lives of children with ASD and their carers, connecting professionals from the robotic community with experts in the area of ASD makes a lot of sense.

This study aims to contribute to this by providing a systematic overview of objectives that are important for children with autism and to provide a mapping of available robots to these objectives. This may facilitate the awareness and creation of common understanding between robot developers and ASD professionals (both educators at (special) schools or therapists working in care settings) who are (intending to become) active in the area of robot assisted therapy for children with autism. For ASD professionals it may provide an overview of robots that are currently presented in peer reviewed literature. For the robotic developers on the other hand, it may give insight into relevant ASD domains and objectives that professionals in the field are actually working on.

In short, this research entailed two main goals:

1. To create an overview of relevant therapy and educational objectives that professionals are actually working on in practice for children with ASD.

2. To identify robots focusing on children with ASD that are presented in peer reviewed articles and to relate them to the overview of objectives.

\section{Methods}

A mixed methods approach was used in this study. For the part of creating an overview of ASD objectives that professionals work on for children with ASD, focus group sessions were carried out in which practitioners from the field were involved. For the part of identifying which robots are presented in peer reviewed journals, a systematic literature study was conducted.

\section{Focus Groups}

Care organisations, medical day care centres and special schools, all specialised in supporting children with ASD, were invited to participate in the focus groups to gain insight into the therapy and education objectives professionals work on for children with ASD. At each organisation a session was organised at a moment that was most convenient for the participants from that organisation.

The main principles of the Metaplan method were used for conducting the sessions and the data collection (Schnelle 1979). Main principles of this method include collecting individual input of the participants (one idea on one card), then sharing these in the group in an open nonjudgemental brainstorm and ending with organising them collectively.

\section{Participants}

In total nine focus group sessions were conducted with employees from nine organisations who work with children with ASD on a daily basis. One session was organised for each organisation. This relatively high number of sessions was chosen deliberately in order to be able to identify a large range of objectives inherent to the heterogeneous nature of the disorder and to include both therapy and education settings. The participating organisations all 
provide care, therapy or education for children and youngsters with ASD (e.g. special need schools, youth care organisations, centres for orthopedagogical treatment, medical day care centres). Professions of the participants ranged from speech-language pathologist, occupational therapist, applied behaviour analyst, game therapist, special needs teacher, psychologist, family coach, to team leader or director.

\section{Procedure}

For both practical (e.g. busy schedules of care professionals and teachers) and motivational reasons (e.g. increase commitment of professionals), the sessions took place at the premises of the care organisations and/or special schools. The focus groups were carried out in separate sessions (ranging from 4 to 9 participants in each group) at the different locations and took about $2 \mathrm{~h}$ each. All participants in one session were employed by the same organisation. Two researchers from the project team were present in each session, one person in the role of focus group moderator, and the other person as preparation assistant, observer, and note taker. As preparation of each session, informed consent papers, post-its and pens were distributed among each participant. To facilitate both the individual and the group aspect, the procedure consisted of 3 main steps. After an introduction, the participants started with listing as many ASD objectives as they considered to be relevant for children with ASD (independently and individually they wrote down one objective per note). The second step was to discuss these individual notes in the group to share results among participants. Finally, all the separate notes with objectives were collectively organised on a large sheet of paper in the middle of the group. For facilitating grouping of the objectives, a categorisation of 12 overall areas was shown as presented in Wong et al. (2014) on evidence based practices for children, youth and young adults with ASD. Participants were free to change, alter or expand these categories where they considered this appropriate. The goal was not to strive for consensus, but to create a realistic overview of the range of objectives that professionals work on with children with ASD. Differences were considered to be valuable, not troublesome.

\section{Data Analysis}

A picture was taken of the grouping that was done and all notes were collected and digitalised individually. Focus group sessions were recorded (audiotaped, after collecting informed consent) and a transcript was made of each session. The objectives and the clustering that the groups made were collected by two project members who participated in the sessions and they made the overall overview based on these results. An analytical session was organised in which they studied the results and found commonalities or patterns in the mentioned objectives and grouping of the domains. In order to provide a common language for sharing these findings, ICF-CY codes were provided for the objectives. The International Classification of Functioning, Disability and Health (ICF) of the World Health Organisation (WHO) provides a uniform classification of health and health-related domains (World Health Organization 2007). The ICF-CY is the Child and Youth version that is applicable to this study. A member check of the created ASD objectives overview was done by means of an online questionnaire (the participants indicated to agree to the resulting overview) afterwards.

\section{Systematic Literature Study}

\section{Procedure}

Research articles were obtained through an electronic library search (queried in February 2015) according to the principles stated in the Cochrane Handbook (Higgins and Green 2008). A systematic search was conducted in a number of major databases from various disciplines (ranging from social and behavioural sciences to educational to technology expertise). The consulted databases were: PubMed, CINAHL, EMBASE, ERIC, IEEE Xplore digital library, Science Direct, SpringerLink and Taylor and Francis. Furthermore, a Google Scholar search was performed. For a comprehensive search of the literature, search terms were formulated very broadly to increase the likelihood of inclusion of relevant articles. Three main elements of the search query were used: robot, autism and child. The search terms were tailored to the requirements of the respective databases where necessary (e.g. appropriate use of MeSH terms, headings, thesaurus and free text words). Only articles written in English were included and the search was conducted based on the articles metadata. For more details on the search strategy used in the literature study we refer to the "Appendix".

\section{Data Extraction}

All full articles were read by the first author who extracted the following data from these articles: what robot is used in the presented study and for what ASD objective(s) or goal(s) is this robot applied in the specific study? The ASD objectives overview based on the results from the focus groups was used as a framework (see Table 2). For each study, the robot used and the objective that best represents the goals described by the authors was identified. These goals were matched with the objectives in the framework, resulting in a mark in the table. 


\section{Results}

\section{Therapy and Educational Objectives for Children with ASD (From Focus Groups)}

\section{Descriptive Characteristics}

In total, 53 ASD professionals (41 female, 12 male) participated in nine focus group sessions. They were all trained and specialised in working with children with ASD, mostly in multidisciplinary teams with varying backgrounds such as child psychology, psychiatry, behavioural science, speech and language therapy, occupational therapy, physiotherapy, art therapy, special needs education and care or general management. The years of working experience in practice ranged from 1 to 35 years. The large majority of the professionals had an experience of over 5 years (average 12.7 years, SD 7.8 years).

\section{Overview of Therapy and Educational Objectives for Children with ASD}

During all these sessions, a total number of 489 notes with ASD objectives were created by the participants describing the therapy or educational goals that they consider important for children with ASD. The first two columns of Table 2 present the results from the focus groups and highlight the main areas and objectives that ASD professionals identified as being important goals. The overview is divided into nine main domains; communication, social/ interpersonal interactions and relations, self-care/independent living, play, emotional wellbeing, sensory experiences and coping, motor experiences and skills, preschool skills, and functioning in daily reality; each of these domains entail a number of more concrete and specific objectives (linked to ICF-CY codes) (World Health Organization 2007).

Some domains are very closely related, such as communication and social/interpersonal interactions and relations. The objectives within the domains provide more detail of what is meant, and the domain provides the overall context. Participants indicated that all objectives are relevant for children on the spectrum; but not all objectives are urgent for a particular child at any given moment in time. Due to the heterogeneous nature of ASD, the objectives that professionals worked on, differed per child and were dynamic over time. Professionals mentioned that they choose to apply different interventions to work on this variety of objectives. Professionals work with more than one child with ASD, so in their working day at special schools, medical day care centres or ASD care organisations, they are working on multiple objectives using different interventions to achieve their goals. There was a relative equal mix of people working for care organisations providing therapy and professionals working for special needs schools or medical day care centres.

Participants mentioned that a large share of their work is targeted at supporting children to be able to live as independent as possible in different areas of life (e.g. home, school/work, hobby, society). They argued that they focused on improving children's level of functioning in daily life rather than focusing on the problems they experience.

Tuning of and deciding upon the objectives per individual child is an important task done. Professionals stressed that each child with autism is unique and an enormous variety can be seen between the needs, capacities and challenges of these children. Therefore, they indicated tailoring the objectives to the needs of a particular child at a given time is a crucial task for them. As a result, the range of objectives that professionals worked on differed per individual child and changed over time within each child as well. What works perfectly for one child might lead to a panic attack or discomfort for the other child. Adjusting the detailed and flexible application of interventions to each child is often required to meet the delicate needs of each child. What is a natural reaction for the one child, might seem an almost impossible demand for the other.

\section{Available Robots (From Literature Study)}

With all this in mind, we were interested in how robotic support fits in this ASD objectives overview that professionals work with. The initial broad search of the literature search yielded 578 unique references (see Fig. 1 for a visual representation).

Three reviewers from the research team (RvdH, ML, and the first author $\mathrm{CH}$ ) first screened the titles of these articles according to predetermined inclusion criteria using a 3 -point scale $(0=$ not relevant, $1=$ maybe relevant, $2=$ relevant). The reviewers were instructed by means of a scoring and inclusion manual. In order to minimise the risk for excluding relevant articles, all references with a minimal score of 2 were included. The second step, abstracts screening $(\mathrm{n}=387)$, was conducted by the same 3 reviewers, again based on a scoring instruction manual. For more details about the inclusion criteria manuals we refer to the "Appendix". The search resulted in 36 articles that matched our criteria (e.g. robot for children with ASD, tested with children of the target group). Only peer reviewed journal articles were included; book chapters and conference proceedings were excluded.

The reviewers' Inter-Rater Agreement (weighted Cohen's kappa coefficient) for scoring the titles and 


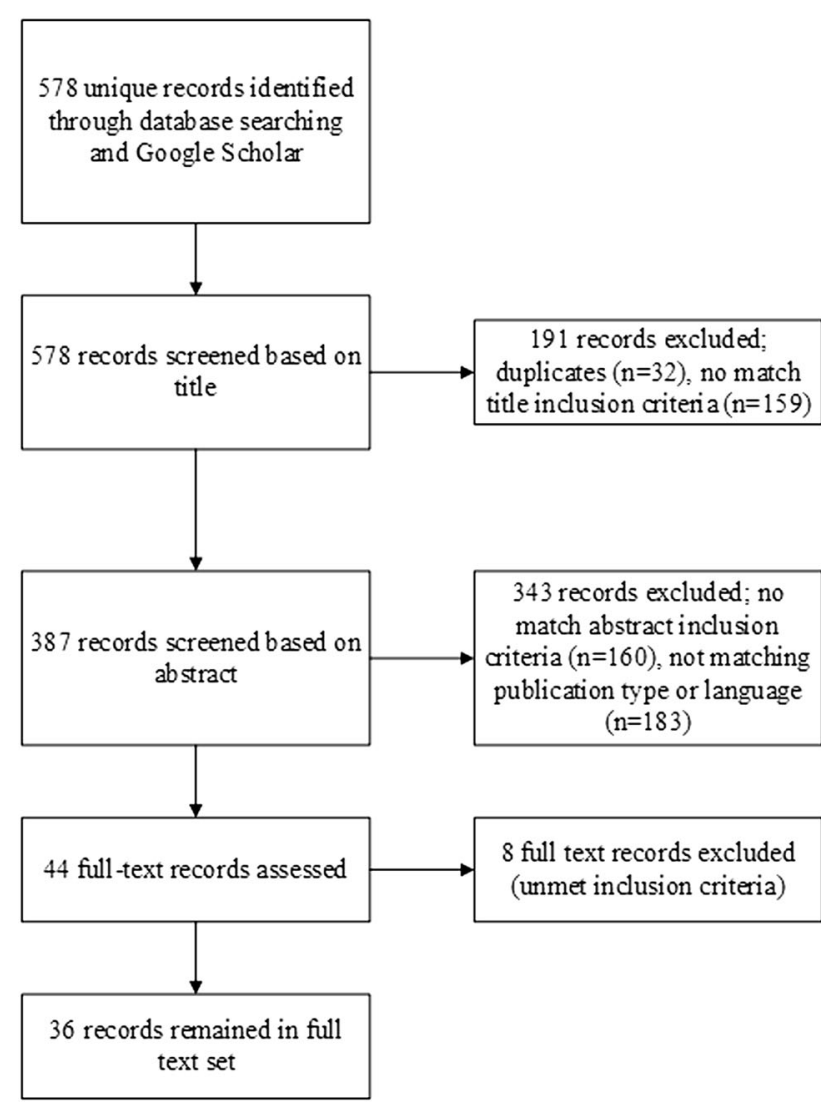

Fig. 1 Flowchart of steps in systematic literature search

scoring the abstracts between the three reviewers varied between 0.76 and 0.85 (average 0.81 ).

\section{Identifying Robots for Children with an Autism Spectrum Disorder}

In total 14 different robots were identified. A number of robots were discussed in multiple articles (e.g. NAO, Robota, Probo, Keepon, Isobot, GIPY-1, KASPAR, and Labo-1), while other robots were identified in one article only (e.g. Cat robot, Tito, HOAP 3, Robot arm, Pleo and Ifbot) (see Table 1).

One characteristic in which these robots differed was the operation mode, which can vary on a scale ranging from a remote controlled robot (used in many Wizard of $\mathrm{Oz}$ studies) to a semi-autonomous robot to a (fully) autonomous robot. Fully autonomous robots (or systems) can act and perform tasks with a high degree of autonomy; without direct input of a person (Bartneck and Forlizzi 2004).

In this case, often, a larger technical environment (e.g. with intelligent sensing camera's and smart algorithms) is used to observe, analyse and provide input to the robot to act based on a (small) number of pre-programmed tasks. A (remote) controlled robot on the other hand is operated by a person. The operation mode has consequences for the applicability in practice; many differences exists, for example with respect to the technical complexity, infrastructural demands for the use environment, differences in flexibility, price differences as well as different requirements for the people using them.

The operating mode of the presented robots varies between a fully (tele-)operated Wizard of $\mathrm{Oz}$ style, to a semi-autonomous or a fully autonomous style. In most of the identified studies, $(\mathrm{n}=19,60 \%)$ the robots are teleoperated and use a kind of Wizard of $\mathrm{Oz}$ mode, meaning that a person is (remotely) controlling the robot's behaviour without the child noticing this. In $31 \%$ of the identified studies, the robots $(n=10)$ are used in an autonomous manner meaning that no person is controlling the robot, but an autonomous system determines the entire behaviour of the robot. Often an extensive technical and intelligence system is required besides the robot alone to realize a fully autonomous (technical) environment (e.g. sensor input based control logic, vision or camera systems, (head, body parts or eye) tracking devices like a cap to monitor/detect/track child's behaviour, gazing or even vital signs). In $9 \%$ (3 studies), the robot was used in a semiautonomous manner, in which part of the robot's behaviour is triggered autonomously based on the child's behaviour, and a part of the robot's actions are tele-operated by a person.

The robot Nao was used in all the three operating modes, in some studies it functioned completely autonomous, in one study semi-autonomous and in others it was tele-operated. Most other robots where most often used in a tele-operation manner except for Robota, HOAP-3, KASPAR and Labo-1 (they were either functioning autonomous or semi-autonomous).

Table 2 shows the overview of identified robots mapped to the ASD objectives overview that was created on the basis of the results of the focus groups. It shows which robots relate to what objectives. Together these 14 robots relate to 24 different objectives out of the total number of 74 ASD objectives identified by the professionals.

Some robots (e.g. NAO, Robota, Probo, Keepon, Isobot, Tito, GIPY-1, KASPAR, Ifbot, Labo-1) have been applied to multiple objectives, and other robots have been reported in the context of one ASD objective only (e.g. cat robot, HOAP 3, Robot arm and Pleo). The Nao robot is discussed in the highest number of different articles (8) and addresses 5 different objectives. KASPAR is presented in 3 articles in the set and is applied to address 12 different objectives.

A number of objectives are targeted by these 14 robots while a rather large number of objectives $(n=50)$ remain unaddressed by the robots. Objectives that were most often targeted (either presented in more than 2 articles and/or addressed by more than 2 robots) are: imitation (in domain 
Table 1 Identified robots in peer reviewed journals applied in studies with children with ASD

\begin{tabular}{|c|c|c|c|c|}
\hline Robot & Picture $^{\mathrm{a}}$ & Description & $\begin{array}{l}\text { Operating } \\
\text { mode }\end{array}$ & References \\
\hline \multirow[t]{8}{*}{ Nao } & & \multirow{8}{*}{$\begin{array}{l}\text { Nao is commercially available, programmable, has multiple degrees of freedom, } \\
\text { humanoid robotic platform used in multiple contexts, domains and for varying } \\
\text { target groups. More information on Nao can be found on http://www.aldebaran. } \\
\text { com/ }\end{array}$} & Autonomous & $\begin{array}{l}\text { (Warren et al. } \\
\text { 2014) }\end{array}$ \\
\hline & & & $\begin{array}{l}\text { Semi- } \\
\text { Autonomous }\end{array}$ & $\begin{array}{l}\text { (Warren et al. } \\
\text { 2013) }\end{array}$ \\
\hline & & & $\begin{array}{l}\text { Controlled/ } \\
\text { Wizard of } \\
\mathrm{Oz}\end{array}$ & $\begin{array}{l}\text { (Tapus et al. } \\
\text { 2012) }\end{array}$ \\
\hline & & & Autonomous & $\begin{array}{l}\text { (Anzalone } \\
\text { et al. 2014) }\end{array}$ \\
\hline & & & Autonomous & $\begin{array}{l}\text { (Bekele et al. } \\
\text { 2014) }\end{array}$ \\
\hline & & & $\begin{array}{l}\text { Controlled/ } \\
\text { Wizard of } \\
\mathrm{Oz}\end{array}$ & $\begin{array}{l}\text { (Huskens et al. } \\
\text { 2014) }\end{array}$ \\
\hline & & & $\begin{array}{l}\text { Controlled/ } \\
\text { Wizard of } \\
\mathrm{Oz}\end{array}$ & $\begin{array}{l}\text { (Huskens et al. } \\
\text { 2013) }\end{array}$ \\
\hline & & & Autonomous & $\begin{array}{l}\text { (Bekele et al. } \\
\text { 2013) }\end{array}$ \\
\hline \multirow[t]{3}{*}{ Robota } & & \multirow[t]{3}{*}{$\begin{array}{l}\text { Robota is a non-commercially available, multiple degrees of freedom doll-shaped } \\
\text { mini-humanoid robot, that was created on the base of a commercially available } \\
\text { doll }\end{array}$} & $\begin{array}{l}\text { Controlled/ } \\
\text { Wizard of } \\
\mathrm{Oz}\end{array}$ & $\begin{array}{l}\text { (Billard et al. } \\
\text { 2007) }\end{array}$ \\
\hline & & & $\begin{array}{l}\text { Controlled/ } \\
\text { Wizard of } \\
\text { Oz }\end{array}$ & $\begin{array}{l}\text { (Robins et al. } \\
\text { 2006) }\end{array}$ \\
\hline & & & $\begin{array}{l}\text { Controlled/ } \\
\text { Wizard of } \\
\mathrm{Oz}\end{array}$ & $\begin{array}{l}\text { (Robins et al. } \\
\text { 2005) }\end{array}$ \\
\hline \multirow[t]{2}{*}{ Probo } & & \multirow{2}{*}{$\begin{array}{l}\text { Probo is developed as multi-disciplinary research platform for human-robot } \\
\text { interaction and to develop robot assisted therapies for different children. At the } \\
\text { time of writing there are plans for a start-up for Probo. http://probo.vub.ac.be/ } \\
\text { Probo/buy.htm }\end{array}$} & $\begin{array}{l}\text { Controlled/ } \\
\text { Wizard of } \\
\mathrm{Oz}\end{array}$ & $\begin{array}{l}\text { (Anamaria } \\
\text { et al. 2013) }\end{array}$ \\
\hline & & & $\begin{array}{l}\text { Controlled/ } \\
\text { Wizard of } \\
\mathrm{Oz}\end{array}$ & $\begin{array}{l}\text { (Vanderborght } \\
\text { et al. 2012) }\end{array}$ \\
\hline \multirow[t]{3}{*}{ Keepon } & & \multirow[t]{3}{*}{$\begin{array}{l}\text { Keepon is a commercially available toy robot, designed to study social } \\
\text { development by interacting with children, not specifically for ASD. More } \\
\text { information at: http://www.mykeepon.com }\end{array}$} & $\begin{array}{l}\text { Controlled/ } \\
\text { Wizard of } \\
\mathrm{Oz}\end{array}$ & $\begin{array}{l}\text { (Kozima et al. } \\
\text { 2007) }\end{array}$ \\
\hline & & & $\begin{array}{l}\text { Controlled/ } \\
\text { Wizard of } \\
\mathrm{Oz}\end{array}$ & $\begin{array}{l}\text { (Kozima et al. } \\
\text { 2009) }\end{array}$ \\
\hline & & & $\begin{array}{l}\text { Controlled/ } \\
\text { Wizard of } \\
\mathrm{Oz}\end{array}$ & $\begin{array}{l}\text { (Costescu et al. } \\
\text { 2014) }\end{array}$ \\
\hline $\begin{array}{l}\text { Cat } \\
\text { robot }\end{array}$ & & $\begin{array}{l}\text { An early model of a robot with cat design features, non-commercially available, } \\
\text { developed by a multi-disciplinary researchers group (for children with ASD) }\end{array}$ & $\begin{array}{l}\text { Controlled/ } \\
\text { Wizard of } \\
\text { Oz }\end{array}$ & $\begin{array}{l}\text { (Mun et al. } \\
\text { 2014) }\end{array}$ \\
\hline \multirow[t]{2}{*}{ I-sobot } & & \multirow[t]{2}{*}{$\begin{array}{l}\text { I-sobot is a very small commercially available "humanoid" robot: http://www. } \\
\text { isobotrobot.com/eng/ }\end{array}$} & $\begin{array}{l}\text { Controlled/ } \\
\text { Wizard of } \\
\mathrm{Oz}\end{array}$ & $\begin{array}{l}\text { (Srinivasan } \\
\text { et al. 2013) }\end{array}$ \\
\hline & & & $\begin{array}{l}\text { Controlled/ } \\
\text { Wizard of } \\
\mathrm{Oz}\end{array}$ & $\begin{array}{l}\text { (Kaur et al. } \\
\text { 2013) }\end{array}$ \\
\hline
\end{tabular}


Table 1 continued

\begin{tabular}{|c|c|c|c|c|}
\hline Robot & Picture $^{\mathrm{a}}$ & Description & $\begin{array}{l}\text { Operating } \\
\text { mode }\end{array}$ & References \\
\hline Tito & & $\begin{array}{l}\text { Tito does not seem to be commercially available, it was built using other } \\
\text { robot's existing modular distributed subsystems from https://introlab.3it. } \\
\text { usherbrooke.ca/mediawiki-introlab/index.php/CRI }\end{array}$ & $\begin{array}{l}\text { Controlled/ } \\
\text { Wizard of } \\
\mathrm{Oz}\end{array}$ & $\begin{array}{l}\text { (Duquette et al. } \\
\text { 2008) }\end{array}$ \\
\hline \multirow[t]{2}{*}{$\mathrm{GIPY}^{\mathrm{b}}$} & & \multirow[t]{2}{*}{$\begin{array}{l}\text { GIPY is a non-commercially available, cylindrical-shaped robot home made } \\
\text { by IBISC }\end{array}$} & $\begin{array}{l}\text { Controlled/ } \\
\text { Wizard of } \\
\mathrm{Oz}\end{array}$ & $\begin{array}{l}\text { (Giannopulu and } \\
\text { Pradel 2012) }\end{array}$ \\
\hline & & & $\begin{array}{l}\text { Controlled/ } \\
\text { Wizard of } \\
\mathrm{Oz}\end{array}$ & $\begin{array}{l}\text { (Giannopulu and } \\
\text { Pradel 2010) }\end{array}$ \\
\hline Hoap 3 & & $\begin{array}{l}\text { Hoap } 3 \text { a programmable Linux robot developed by Fujitsu Automation in } \\
\text { Japan that was commercially available. HOAP stands for "Humanoid for } \\
\text { Open Architecture Platform". http://home.comcast.net/ jtechsc/HOAP-3_- } \\
\text { Spec_Sheet.pdf }\end{array}$ & Autonomous & $\begin{array}{l}\text { (Fujimoto et al. } \\
\text { 2011) }\end{array}$ \\
\hline \multirow[t]{4}{*}{ KASPAR } & & \multirow{4}{*}{$\begin{array}{l}\text { KASPAR, a humanoid robot designed by University of Hertfordshire as } \\
\text { therapeutic toy for children with autism. Commercialisation plans for } \\
\text { KASPAR are in progress. http://www.herts.ac.uk/kaspar/introducing-kaspar/ } \\
\text { developing-kaspar }\end{array}$} & Autonomous & $\begin{array}{l}\text { (Wainer et al. } \\
\text { 2013) }\end{array}$ \\
\hline & & & $\begin{array}{l}\text { Semi- } \\
\text { Autonomous }\end{array}$ & $\begin{array}{l}\text { (Robins and } \\
\text { Dautenhahn } \\
\text { 2014) }\end{array}$ \\
\hline & & & $\begin{array}{l}\text { Semi- } \\
\text { Autonomous }\end{array}$ & $\begin{array}{l}\text { (Costa et al. } \\
\text { 2014) }\end{array}$ \\
\hline & & & Autonomous & $\begin{array}{l}\text { (Wainer et al. } \\
\text { 2014) }\end{array}$ \\
\hline $\begin{array}{c}\text { Robot } \\
\text { arm }\end{array}$ & not available & $\begin{array}{l}\text { A non-commercially available robotic arm model performing a reach-to-grasp } \\
\text { action towards a spherical object }\end{array}$ & $\begin{array}{l}\text { Controlled/ } \\
\text { Wizard-of- } \\
\mathrm{Oz}\end{array}$ & $\begin{array}{l}\text { (Pierno et al. } \\
\text { 2008) }\end{array}$ \\
\hline Pleo & & $\begin{array}{l}\text { Pleo is a commercially available toy dinosaur robot designed to express } \\
\text { emotions and attention, using body movement and vocalization. http://www. } \\
\text { pleoworld.com/pleo_rb/eng/index.php }\end{array}$ & $\begin{array}{l}\text { Controlled/ } \\
\text { Wizard-of- } \\
\mathrm{Oz}\end{array}$ & (Kim et al. 2013) \\
\hline \multirow[t]{2}{*}{ Labo-1 } & & \multirow[t]{2}{*}{$\begin{array}{l}\text { Robot Labo-1 is a platform with four wheels that drives and turns. http://www. } \\
\text { aai.ca/robots/labo1.html }\end{array}$} & Autonomous & $\begin{array}{l}\text { (Dautenhahn } \\
\text { 2007) }\end{array}$ \\
\hline & & & Autonomous & $\begin{array}{l}\text { (Dautenhahn and } \\
\text { Werry 2004) }\end{array}$ \\
\hline ifbot & & Ifbot robot was used as a prompter for showing different facial expressions & $\begin{array}{l}\text { Controlled/ } \\
\text { Wizard-of- } \\
\mathrm{Oz}\end{array}$ & (Lee et al. 2012) \\
\hline
\end{tabular}

a All pictures are used with permission of the authors

b From Giannopulu (2013) and Giannopulu and Watanabe (2016) copied with the permission of the author

Social/Interpersonal interaction and relations; 7 articles, 5 different robots), turn-taking behaviour (in domain Social/ Interpersonal interaction and relations; 5 articles, 3 different robots), imitation (in domain Play; 4 articles, 3 different robots), collaboration/joint attention (in domain Social/Interpersonal interaction and relations; 5 articles, 2 different robots), playing together-collaborative play (in domain Play; 3 articles, 2 different robots), and attention (in domain Social/Interpersonal interaction and relations; 3 articles, 2 different robots).

Table 2 also shows the number of robots that provided support to the different domains. The most commonly addressed domains are: "Social/Interpersonal interactions and relations" (11 robots), "Play" (8 robots) and "Communication" (4 robots). The domain of "Self-care, independent living" is left unaddressed by all robots. 
Table 2 Overview of ASD domains and objectives (results from focus groups) with mapping of robots from literature

\begin{tabular}{|c|c|c|c|c|c|c|c|c|c|c|c|c|c|}
\hline Domain & Objectives & $\begin{array}{l}\text { ICF- } \\
\text { CY } \\
\text { code }\end{array}$ & 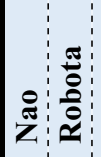 & : & $\begin{array}{l}Z \\
0 \\
0 \\
0 \\
0 \\
0\end{array}$ & 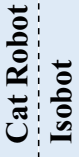 & $\stackrel{1}{1}$ & : & 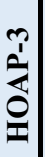 & 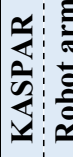 & 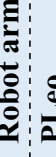 & Dُ & 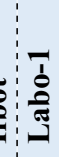 \\
\hline \multirow{9}{*}{ 异 } & Orientation to listen & d115 & & & & & & & & & & & 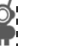 \\
\hline & Making contact & d3 & & & bi: & & & & & b) & & & \\
\hline & Learn a new form of communication & $\mathrm{d} 3$ & & & & & & & & & & & \\
\hline & Understand intention of gesture & $\mathrm{d} 3150$ & & & & & & & & & & & \\
\hline & Understand intention of image / symbol & $\begin{array}{l}\mathrm{d} 3151 \\
\mathrm{~d} 3152 \\
\end{array}$ & & & & & & & & & & & \\
\hline & Understand intention of word & $\mathrm{d} 310$ & & & & & & & & & & & \\
\hline & Use gesture & $\mathrm{d} 315$ & & & & & & & & & & & \\
\hline & Use nonverbal abilities & d 335 & & & & & & & & & & & 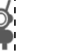 \\
\hline & Talk - use verbal abilities & $\mathrm{d} 330$ & & & & & & & & & & a) & ; \\
\hline \multirow{12}{*}{ 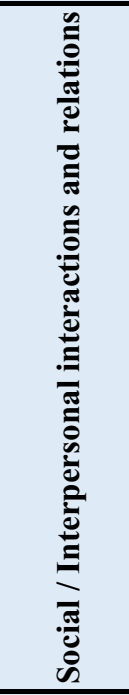 } & Imitation & d130 & bi & & & & & & (1) & & (5) & & \\
\hline & Attention & b140 & bi & & & & & & & bi: & & & \\
\hline & $\begin{array}{l}\text { Appropriately cope with own anger / } \\
\text { sadness /... }\end{array}$ & d7202 & & & & & & & & & & & \\
\hline & $\begin{array}{l}\text { Awareness of feelings, wishes, behaviour, } \\
\text { thoughts of others }\end{array}$ & d7104 & & 9. & & & & & & & & & \\
\hline & Appropriately react to behaviour of others & d7 & & & (bi & & & & & bi & & & \\
\hline & $\begin{array}{l}\text { Social routines (greet, say goodbye, } \\
\text { introduce) }\end{array}$ & d72 & & a) & & & & & & & & & \\
\hline & Turn taking (behaviour) & d720 & bi & & & & & & & bi & & & 6) \\
\hline & Respect / value others (or things) & $\mathrm{d} 71$ & & & & & & & & 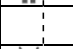 & & & \\
\hline & $\begin{array}{l}\text { Appropriate behaviour w.r.t. physical } \\
\text { proximity / contact or personal space }\end{array}$ & d7 & & & & & & & & boi & & & \\
\hline & Collaboration / joint attention & b1403 & bi: & & & & 8 & & & & & & \\
\hline & Ask for help & $\mathrm{d} 132$ & & & 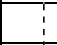 & & & & & & & & \\
\hline & Conflict management & $\mathrm{d} 175$ & & & 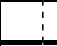 & & & & & 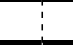 & & & 1 \\
\hline \multirow{7}{*}{ 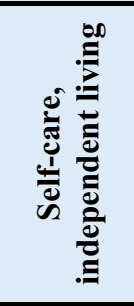 } & Potty training & $\mathrm{d} 53$ & & & 4 & & & & & 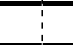 & & & 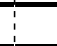 \\
\hline & Eating, drinking & $\begin{array}{l}\mathrm{d} 550 \\
\mathrm{~d} 560\end{array}$ & & & & & & & & & & & \\
\hline & (un)Dressing & $\mathrm{d} 540$ & & & 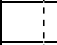 & & & & & 1 & & & \\
\hline & Self-care, personal hygiene & $\mathrm{d} 5$ & & & 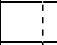 & & & & & 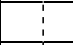 & & & \\
\hline & Domestic skills & d6 & i & & 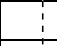 & & t & & & 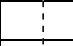 & 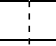 & & 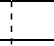 \\
\hline & Mobility & $\mathrm{d} 4$ & & & 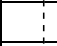 & & 4 & & & 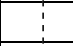 & 7 & & 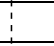 \\
\hline & Hobbies, leisure time & d920 & & & 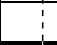 & & & & & 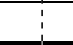 & & & \\
\hline \multirow{7}{*}{$\frac{\vec{a}}{2}$} & Imitation & $\mathrm{d} 130$ & (d) & & 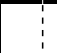 & & b' & & & 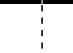 & & & (c) \\
\hline & Develop interest in play & $\mathrm{d} 8808$ & & & 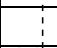 & & 4 & 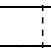 & & 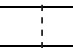 & 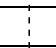 & & 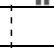 \\
\hline & Development own play & $\mathrm{d} 880$ & & & bi & & & bi & & & & & \\
\hline & $\begin{array}{l}\text { Parallel play (next to each other, same } \\
\text { material) }\end{array}$ & $\mathrm{d} 8802$ & & b) & & & & & & & & & \\
\hline & Playing together - collaborative play & $\mathrm{d} 8803$ & bi & & & & & & & bi & & & \\
\hline & Variation in play (expand play) & $\mathrm{d} 8808$ & 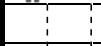 & & 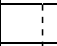 & & 7 & & & 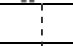 & 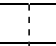 & & 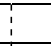 \\
\hline & Negotiate about rules & $\mathrm{d} 8808$ & 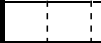 & & 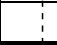 & 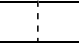 & & 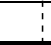 & & 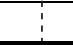 & 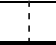 & & 1 \\
\hline
\end{tabular}


Table 2 continued

\begin{tabular}{|c|c|c|c|c|c|c|c|c|c|c|c|c|c|c|c|c|}
\hline Domain & Objectives & $\begin{array}{l}\text { ICF- } \\
\text { CY } \\
\text { code }\end{array}$ & 㐘 & 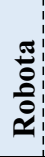 & $\begin{array}{l}8 \\
\vdots \\
0 \\
2\end{array}$ & 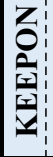 & 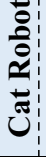 & $\begin{array}{l} \\
\overrightarrow{0} \\
\vdots \\
0\end{array}$ & $\stackrel{1}{0}$ & $\begin{array}{l}7 \\
\vdots \\
0 \\
0\end{array}$ & 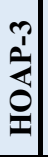 & 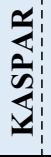 & 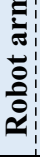 & 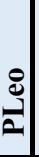 & 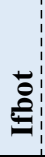 & 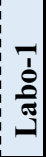 \\
\hline \multirow{8}{*}{ 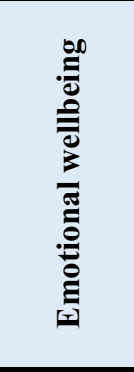 } & Recognise and regulate own emotions & b1520 & & & & & & & & & & & & & & \\
\hline & Self-image, ASD awareness, who am I? & b1800 & & & & & & & & & & bit & & & & \\
\hline & $\begin{array}{l}\text { Resilience (detect and guard limits, defend } \\
\text { oneself) }\end{array}$ & b1268 & & & & & & & & & & & & & & \\
\hline & Confidence, self esteem & b1266 & & & & & & & & & & & & & & \\
\hline & Rest, relaxation & b152 & & & & & & & & & & & & & & \\
\hline & Having fun, experiencing pleasure & d920 & & & & & & & & & & & & & & \\
\hline & Safety & b152 & & & & & & & & & & & & & & \\
\hline & Making thoughts positive & b1251 & & & & & & & & & & & & & & \\
\hline \multirow{5}{*}{ 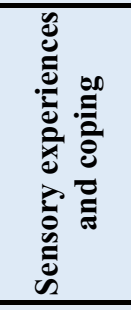 } & $\begin{array}{l}\text { Adequate processing sensory triggers, } \\
\text { regulate, stimulate }\end{array}$ & b156 & & & & & & & & & & bli & & & & \\
\hline & $\begin{array}{l}\text { Understand what body is "saying" (pee, } \\
\text { hunger, noises) }\end{array}$ & b2 & & & & & & & & & & but & & & & \\
\hline & Change stereotype behaviour & b1250 & & & & & & & & & & & & & & \\
\hline & Prevent panic reactions & b1521 & & & & & & & & & & & & & & \\
\hline & Be able to postpone urge / want & b1304 & & & & & & & & & & biti & & & & \\
\hline \multirow{6}{*}{ 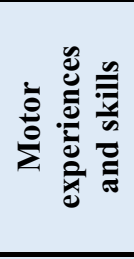 } & Balance and equilibrium & $\mathrm{b} 235$ & & & & & & & & & & & & & & \\
\hline & Body awareness & b260 & & & & & & & & & & & & & & \\
\hline & Grove and fine motor skills & $\mathrm{b} 7$ & & & & & & & & & & & & & & \\
\hline & Movement & $\mathrm{d} 4$ & & & & & & & & & & & & & & \\
\hline & Coordination & b7 & & (1) & & & & & & & & & & & & \\
\hline & Strengthening of muscles & b7306 & & & & & & & & & & & & & & \\
\hline \multirow{14}{*}{ 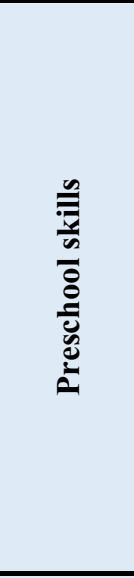 } & Work posture (sit still, no wobbling) & $\mathrm{d} 815$ & & & & & & & & & & & & & & \\
\hline & Train or practice skills & $\mathrm{d} 155$ & & & & & & & & & & & & & & \\
\hline & Be able to start/stop independently & $\mathrm{d} 210$ & & & & & & & & & & & & & & \\
\hline & Work on his/her own, task approach & $\mathrm{d} 2102$ & & & & & & & & & & & & & & \\
\hline & Cope with schedule/programme & $\mathrm{d} 198$ & & & & & & & & & & & & & & \\
\hline & Pose a question / ask for help & $\mathrm{d} 815$ & (1) & & & & & & & & & & & & & \\
\hline & Distinguish main from minor issues & $\mathrm{d} 198$ & & & & & & & & & & & & & & \\
\hline & Follow up instructions & d3102 & & & & & & & & & & & & & & \\
\hline & Execute task (simple / complex task) & $\mathrm{d} 2$ & & & & & & & & & & & & & & \\
\hline & Didactic subjects (e.g. maths, reading) & $\mathrm{d} 820$ & & & & & & & & & & & & & & \\
\hline & Spatial concepts & b114 & & & & & & & & & & & & & & \\
\hline & Learn to wait & $\mathrm{d} 815$ & & & & & & & & & & & & & & \\
\hline & Perseverance & b1254 & & & & & & & & & & & & & & \\
\hline & Learn to choose, make decisions & $\mathrm{d} 177$ & & & & & & & & & & & & & & \\
\hline \multirow{6}{*}{ 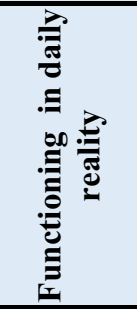 } & $\begin{array}{l}\text { Cope with unexpected situations or } \\
\text { changes }\end{array}$ & $\mathrm{d} 2304$ & & & & & & & & & & & & & & \\
\hline & Flexibility, switch smoothly, less rigid & b1643 & & & & oi & & & & & & & & & & \\
\hline & Problem solving skills & $\mathrm{d} 175$ & & & & & & & & & & & & & & \\
\hline & Taking initiative & d179 & & & & & & & & & b) & bit & & & & \\
\hline & Transfer of skills / knowledge & d179 & & & & & & & & & & & & & & \\
\hline & Open mind to tasting / eating food & b126 & & & & & & & & & & & & & & \\
\hline
\end{tabular}


"Preschool skills" is the domain where the ASD professionals identified most objectives $(n=14)$, however, it can be seen that (only) 1 ("pose a question/ask for help") of these 14 objectives was targeted by 1 robot (Nao) in 1 article. For the domain of "Emotional wellbeing" also 1 robot (KASPAR) could be identified in 1 article addressing 1 objective ("self-image, ASD awareness, who am I").

\section{Discussion}

The main results of this research indicate that professionals work on a broad variety of therapy and/or educational objectives in a wide range of domains for children with ASD and that state of the art robots focuses on only a small set of these objectives.

The wide range of therapy and educational objectives for children with autism, resulting from the focus groups, is in line with the heterogeneous nature of the disorder (American Psychiatric Association 2013). Professionals indicated that they are focused and driven by supporting these children in coping with their ASD in daily life towards independent living rather than trying to "fix" their impairments, challenges or differences. These objectives could be categorised into 9 domains and 74 objectives.

Best matching ICF-CY codes were collected for each objective (World Health Organization 2007). Since the ICF-CY offers an universal standardised categorisation, it is not specifically constructed for children with ASD. Therefore, in some cases it was challenging to find the best matching ICF-CY code to the objectives, so it was ensured that this task was done with utmost care and attention of multiple project members who were actively involved in the sessions with the professionals.

The participants of the focus group sessions are all highly specialised experts in the area of education or therapy for children with ASD. In the Netherlands many children with ASD attend special schools where they receive special education and dedicated therapy at school. This implies that these professionals are highly specialised in autism, and that the groups of children at schools are rather small (maximum 7-12 children in a classroom) and mostly existing of children with autism. This might be different in other countries and is also changing in the Netherlands (more children with autism will be integrated in regular education).

The results of the literature study, on identifying state of the art robots for this target group, showed that at this moment in time a relatively small subset $(n=24)$ of this ASD objectives $(n=74)$ is addressed by the identified robots $(n=14)$, leaving quite a large number of ASD objectives unmet by robotic support.

Most of the reported studies in this work used a teleoperated Wizard of $\mathrm{Oz}$ style in which a person operates the behaviour of the robot. This creates a benefit of flexibility for the human who can sensitively read the social situation and the child and accordingly control the robot to act appropriately. At the same time this also creates a burden (increase of workload) on that person and often extra technical personnel is required to smoothly operate the robot. This is in line with other work stating that few of the current approaches (in robot assisted therapy for children with ASD) use autonomously interactive robots (Thill et al. 2013). Thill et al. (2013) actually call for a need for more autonomous therapeutic robots rather than remote controlled robots.

For a detailed insight into the effects of the robots and types of the studies identified in Table 1, we refer to earlier reviews on the use of robots in the context of ASD (Cabibihan et al. 2013; Diehl et al. 2012). When focusing on the domains, we conclude that the majority of the robot studies were related to 3 of the 9 domains; "Social/Interpersonal interactions and relations", "Play" and "Communication". Other domains such as "Self-care, independent living", "Pre-school skills", "Emotional wellbeing", and "Functioning in daily reality" were (largely) unaddressed by the identified robot studies. This is not a surprising result since the main challenges of children with ASD are indeed related to social and communicative challenges as well as impairments in play behaviours (American Psychiatric Association 2013). Typical ASD objectives in these domains, such as imitation, collaborative play, (joint) attention, as well as turn taking behaviour, were often targeted by (quite similar) robotic support in studies. These rather typical ASD objectives are primary difficulties that children with autism experience that in turn create challenges in different areas of their daily living as can be seen in the overview (for example "follow up instructions"). Robotic solutions can possibly also be of surplus value in other (more indirect) areas as well.

When mapping the robotic studies to the objectives overview, we aimed to find the objective in the overview that matches the focus of specific study best.

The overview can function as creating awareness of the scope of objectives for children with autism that professionals are actually working on with children with ASD. The intention is not to suggest to use a robot for all objectives for all children. Developing meaningful robot assisted therapy requires a profound understanding of the target group. To better understand the possibilities and impossibilities, appropriateness or inappropriateness of robotic support in the objectives and domains, more research is needed. For example, using robots to learn children to follow up instructions might be more appropriate than using robots to teach them to negotiate about rules. Moreover, professionals might express a stronger need for additional interventions targeting some objectives rather than others. And some children might react better to interventions using robots than others. 
The next step would be that these objectives will be specified and translated into possible robotic interventions that matches the user requirements of both the children and professionals.

As indicated before, especially the diverse and heterogeneous nature of the ASD calls for a high degree of tuning/ adaptation/personalisation or individualisation in the interventions. It asks for a bottom-up, client centred, tailor made approach. Robotic interventions might be very well capable of addressing this need due to their many potential advantages, however, current state of the art robots for children with ASD has probably not reached its full potential yet in terms of interventions/clinical application. Furthermore, most of these studies (still) present the robots [operated by a (technical) researcher] as a platform focusing on robot-child interactions rather than a robot assisted intervention in the hands of the care professional embedded into care protocols and actual therapy/educational settings. This is in line with conclusions of earlier work (Bekele et al. 2014; Diehl et al. 2012). This also corresponds with a meta-analysis done on innovative technology based interventions that concluded that no evidence based robot interventions are currently available for children with ASD (Grynszpan et al. 2014). Robot assisted interventions can be seen as a therapy or education tool in the hands of the professionals. In order to be used, these robots do not only have to address the needs of the children with ASD, but they also have to be sensitive to the requirements posed by the professionals. Making it work/happen in practice requires more than the stability and availability of a meaningful robot. If the robot is not incorporated in the care or education provision and application of interventions no child nor professional will ever benefit from robots. In order to do so, we need to better understand the professionals requirements for robot assisted interventions. It is crucial to investigate how robotbased (interaction) scenarios can be integrated into existing therapy/education environments for children with autism (Shamsuddin et al. 2015). Taking this work to the next level implies moving beyond focusing solely on the robot towards embedding a robot in a clinical intervention or therapy/education protocol. For this, more applied research in an education/therapeutic context (e.g. in a school or care setting) is required to understand better what is needed in terms or intervention/education requirements from ASD professionals, the envisioned end-users of robot assisted therapy.

Research has proven the efficacy of many technologies for people with autism. However, although these tools are useful, often these are rather general in nature, resulting in a lack of personalisation to a person's specific needs (American Psychiatric Association 2013). It is crucial to design appropriate interventions that can be tailored to the individual needs of this target group in order to increase people's independence and productive functioning (Volkmar et al. 2014).
Technology becomes more and more part of everyday life and activities, and it is inevitable that technology will be integrated into autism intervention as well (McCleery 2015). However, in order to specify and develop meaningful robot based interventions, it is crucial that professionals, stakeholders as well as technology developers co-create (McCleery 2015). This research aimed to provide a the base for understanding relevant objectives in the therapy and/or education of children with ASD, which is a necessary first step in user centred design process for developing robot assisted interventions. In conclusion, this work is expected to be valuable for experts in the area of children with ASD who are considering using robots as innovative tools in education or therapy. Simultaneously, it is considered to be useful for robot developers who are interested in application domains and are in need of a better understanding of the needs of the target group of children with autism.

It may contribute to the creation of common understanding between ASD professionals and robot developers in their (joined) mission to create meaningful robot interventions for children with autism in the quest to support these children to become the best possible version of themselves in life.

Acknowledgments This work has been conducted in the context of the project "Social robots in care" (Project Number PRO-4-10) (partially) funded by the RAAK-PRO programme of SIA (Stichting Innovatie Alliantie). This is a program from the Dutch ministry of education, culture and science to stimulate collaboration between public and private organisations. The authors sincerely thank our beloved friend and colleague Gert Jan Gelderblom ${ }^{\dagger}$ for his appreciated dedication and devotion to this research as well as to the entire field of assistive technologies for people in need of support. Additionally, this work would not have been possible without the valued input of all the ASD professionals in the organisations who actively and so willingly participated in the focus groups. Furthermore, the authors thank Renée van den Heuvel for helping in scoring the titles and abstracts in the literature study. A robot icon from Freepik.com is used to create Table 2.

Author Contributions The research presented in this article is part of the $\mathrm{PhD}$ work of the first author $(\mathrm{CH})$ who is the main researcher in this project and author of this article. The second author (ML) is the copromoter of the $\mathrm{PhD}$ student and guided the research process, contributed to the systematic literature study and supported in writing this manuscript. The third author' (RJ) contribution consists in supporting the PhD student with the conduction of the focus groups, the data collection, as well as analysis of the data of the focus groups. The fourth author $(\mathrm{LdW})$ is the main supervisor and promoter in this project.

\section{Compliance with Ethical Standards}

Conflict of interest The authors declare that they have no conflict of interest.

Open Access This article is distributed under the terms of the Creative Commons Attribution 4.0 International License (http://crea tivecommons.org/licenses/by/4.0/), which permits unrestricted use, distribution, and reproduction in any medium, provided you give appropriate credit to the original author(s) and the source, provide a 
link to the Creative Commons license, and indicate if changes were made.

\section{Appendix}

\section{Search Strategy Used in Literature Study}

Queries were tailored to the specific databases used, the query for PUBMED for example was

\section{AUTISM + CHILD + ROBOT}

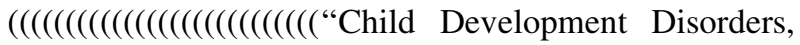
Pervasive"[Mesh]) OR “Asperger Syndrome"[Mesh]) OR "Autistic Disorder"[Mesh]) OR "pervasive child development disorders") OR "pervasive development disorders") OR “pervasive development disorder") OR “autism spectrum disorders") OR "autism spectrum disorder") OR "asperger's syndrome") OR "aspergers syndrome”) OR "asperger's disease") OR “asperger's disorder") OR "aspergers disorder") OR "asperger disorder") OR "asperger disease") OR asperger*) OR "kanner's syndrome") OR "kanner syndrome") OR "kanners syndrome") OR “infantile autism") OR "early infantile autism”) OR ASD) OR PDD*) OR PDD-NOS) OR autis*)) AND (((()(“Child”[Mesh]) OR “Child, Preschool”[Mesh]) OR "preschool child") OR preschool children) OR child*) OR teenager $))$ AND (((()(“robotics" [Mesh]) OR robotics) OR "humanoid") OR "non humanoid") OR "socially assistive robotics") OR SAR) OR robot* [tiab])

The number of results found per source is displayed in the Table 3.

Table 3 Number of references found per source

\begin{tabular}{lc}
\hline Source & \# of results \\
\hline CINAHL & 20 \\
PUBMED & 76 \\
EMBASE & 5 \\
ERIC & 10 \\
IEEE & 175 \\
Science Direct & 106 \\
SpringerLink & 96 \\
Taylor\&Francis & 1 \\
Google Scholar & 117 \\
Journal Social Robotics & 6 \\
Manual search & 12 \\
Total references incl duplicates & $\mathbf{6 2 3}$ \\
Remove bachelor/master thesis & 7 \\
Remove duplicates & 38 \\
Total unique references & $\mathbf{5 7 8}$ \\
\hline
\end{tabular}

The bold digits show that these are (sub)totals

\section{Inclusion Criteria for Scoring Based on Titles Only}

- overall question: which robots are used (in the therapy or education) for children with an autism spectrum disorder?

- only titles are provided to minimize the risk for biases (e.g. based on authors or journals)

- English language

- (semantically, not necessarily literally) in title: autism $O R$ robots $O R$ children

- we don't want to restrict too much already only based on the titles. In the next step of scoring abstracts, we will look for autism AND robots AND children. So if in doubt, score 1.

- no medical nor surgical robots

- scorings scores for the titles of the articles

- $0=$ not relevant

- 1 = maybe relevant

- $2=$ relevant

- All references with a total score of 3 and higher will go to the next step (scoring abstracts)

\section{Inclusion Criteria for Scoring Based on Abstracts}

- English language

- type: journals, conference proceedings, book chapters

- autism + robots + children

- Which robots are used (in the therapy or education) for children with an autism spectrum disorder?

- no medical or surgical robots

- Scorings scores

- $0=$ not relevant

- 1 = maybe relevant

- $2=$ relevant

\section{References}

American Psychiatric Association. (2013). Diagnostic and statistical manual of mental disorders: DSM-5. DSM-5. American Psychiatric Publishing.

Anamaria, P. C., Simut, R., Pintea, S., Saldien, J., Rusu, A., Daniel, D., et al. (2013). Can the social robot Probo help children with autism to identify situation-based emotions? A series of single case experiments. International Journal of Humanoid Robotics, 10(03), 1350025. doi:10.1142/S0219843613500254.

Anzalone, S. M., Tilmont, E., Boucenna, S., Xavier, J., Jouen, A. L., Bodeau, N., et al. (2014). How children with autism spectrum disorder behave and explore the 4-dimensional (spatial $3 \mathrm{D}+$ time) environment during a joint attention induction task 
with a robot. Research in Autism Spectrum Disorders, 8(7), 814-826. doi:10.1016/j.rasd.2014.03.002.

Aresti-Bartolome, N., \& Garcia-Zapirain, B. (2014). Technologies as support tools for persons with autistic spectrum disorder: A systematic review. International Journal of Environmental Research and Public Health. doi:10.3390/ijerph110807767.

Baron-Cohen, S., Leslie, A. M., \& Frith, U. (1985). Does the autistic child have a "theory of mind"? Cognition, 21, 37-46. doi:10. 1016/0010-0277(85)90022-8.

Bartneck, C., \& Forlizzi, J. (2004). A design-centred framework for social human-robot interaction. RO-MAN 2004. In 13th IEEE International Workshop on Robot and Human Interactive Communication (IEEE Catalog No. 04TH8759) (pp. 591-594). doi:10.1109/ROMAN.2004.1374827.

Bekele, E., Crittendon, A. J., Swanson, A., Sarkar, N., \& Warren, E. Z. (2014). Pilot clinical application of an adaptive robotic system for young children with autism. Autism: The International Journal of Research and Practice, 18(5), 598-608. doi:10.1177/ 1362361313479454

Bekele, E. T., Lahiri, U., Swanson, A. R., Crittendon, J. A., Warren, Z. E., \& Sarkar, N. (2013). A step towards developing adaptive robot-mediated intervention architecture (ARIA) for children with autism. IEEE Transactions on Neural Systems and Rehabilitation Engineering, 21(2), 289-299. doi:10.1109/TNSRE. 2012.2230188.

Billard, A., Robins, B., Nadel, J., \& Dautenhahn, K. (2007). Building Robota, a mini-humanoid robot for the rehabilitation of children with autism. Assistive Technology, 19(1), 37-49. doi:10.1080/ 10400435.2007.10131864.

Blaxill, M. F. (2004). What's going on? The question of time trends in autism. Public Health Reports, 119, 536-551. doi:10.1016/j.phr. 2004.09.003 (December 2004).

Boucenna, S., Narzisi, A., Tilmont, E., Muratori, F., Pioggia, G., Cohen, D., et al. (2014). Interactive technologies for autistic children: A review. Cognitive Computation, 6(4), 722-740. doi:10.1007/s12559-014-9276-x.

Cabibihan, J.-J., Javed, H., Ang, M., \& Aljunied, S. M. (2013). Why robots? A survey on the roles and benefits of social robots in the therapy of children with autism. International Journal of Social Robotics, 5(4), 593-618. doi:10.1007/s12369-013-0202-2.

Costa, S., Lehmann, H., Dautenhahn, K., Robins, B., \& Soares, F. (2014). Using a humanoid robot to elicit body awareness and appropriate physical interaction in children with autism. International Journal of Social Robotics. doi:10.1007/s12369-0140250-2.

Costescu, C., \& David, D. (2014). Attitudes toward using social robots in psychotherapy. Transylvanian Journal of Psychology, 15(1), 3-20.

Costescu, C. A., Vanderborght, B., \& David, D. O. (2014). Reversal learning task in children with autism spectrum disorder: A robotbased approach. Journal of Autism and Developmental Disorders. doi:10.1007/s10803-014-2319-z.

Dautenhahn, K. (2007). Socially intelligent robots: Dimensions of human-robot interaction. Philosophical Transactions of the Royal Society of London. Series B, Biological sciences, 362(1480), 679-704. doi:10.1098/rstb.2006.2004.

Dautenhahn, K., \& Werry, I. (2004). Towards interactive robots in autism therapy: Background, motivation and challenges. Pragmatics and Cognition, 1, 1-35. doi:10.1075/pc.12.1.03dau (Papert 1980)

Diehl, J. J., Schmitt, L. M., Villano, M., \& Crowell, C. R. (2012). The clinical use of robots for individuals with autism spectrum disorders: A critical review. Research in Autism Spectrum Disorders, 6(1), 249-262. doi:10.1016/j.rasd.2011.05.006.

Duquette, A., Michaud, F., \& Mercier, H. (2008). Exploring the use of a mobile robot as an imitation agent with children with low- functioning autism. Autonomous Robots, 24(2), 147-157. doi:10. 1007/s10514-007-9056-5.

Feil-Seifer, D., \& Mataric, M. (2011). Automated detection and classification of positive vs. negative robot interactions with children with autism using distance-based features. In Proceedings of the 6th International Conference on Human-Robot Interaction-HRI 2011 (p. 323). doi:10.1145/1957656.1957785.

Fridin, M., \& Belokopytov, M. (2014). Acceptance of socially assistive humanoid robot by preschool and elementary school teachers. Computers in Human Behavior, 33, 23-31. doi:10. 1016/j.chb.2013.12.016.

Fujimoto, I., Matsumoto, T., De Silva, P. R., Kobayashi, M., \& Higashi, M. (2011). Mimicking and evaluating human motion to improve the imitation skill of children with autism through a robot. International Journal of Social Robotics, 3(4), 349-357. doi:10.1007/s12369-011-0116-9.

Giannopulu, I. (2013). Multimodal cognitive nonverbal and verbal interactions: The neurorehabilitation of autistic children via mobile toy robots. IARIA International Journal of Advances in Life Sciences, 5.

Giannopulu, I., \& Pradel, G. (2010). Multimodal interactions in free game play of children with autism and a mobile toy robot. NeuroRehabilitation, 27(4), 305-311. doi:10.3233/NRE20100613.

Giannopulu, I., \& Pradel, G. (2012). From child-robot interaction to child-robot-therapist interaction: A case study in autism. Applied Bionics and Biomechanics, 9, 173-179. doi:10.3233/JAD-20110042.

Giannopulu, I., \& Watanabe, T. (2016). Give Children Toys Robots to Educate and/or NeuroReeducate: The Example of PEKOPPA (pp. 205-215). Retrieved from http://link.springer.com/10.1007/ 978-3-319-23832-6_17.

Goldsmith, T. R., \& LeBlanc, L. A. (2004). Use of technology in interventions for children with autism. Journal of Early and Intensive Behavior Intervention, 1(2), 166-178. doi:10.2989/ 1814232X.2011.572353.

Grynszpan, O., Weiss, P. L., Perez-Diaz, F., \& Gal, E. (2014). Innovative technology-based interventions for autism spectrum disorders: A meta-analysis. Autism, 18(4), 346-361. doi:10. $1177 / 1362361313476767$.

Higgins, J. P. T., \& Green, S. (2008). Cochrane handbook for systematic reviews of interventions (Vol. 5). London: Wiley. doi:10.1002/9780470712184.

Huskens, B., Palmen, A., der Werff, M. V., Lourens, T., \& Barakova, E. (2014). Improving collaborative play between children with autism spectrum disorders and their siblings: The effectiveness of a robot-mediated intervention based on Lego ${ }^{\circledR}$ therapy. Journal of Autism and Developmental Disorders. doi:10.1007/ s10803-014-2326-0.

Huskens, B., Verschuur, R., Gillesen, J., Didden, R., \& Barakova, E. (2013). Promoting question-asking in school-aged children with autism spectrum disorders: Effectiveness of a robot intervention compared to a human-trainer intervention. Developmental Neurorehabilitation, 16(5), 345-356. doi:10.3109/17518423.2012. 739212.

Kaur, M., Gifford, T., Marsh, K. L., \& Bhat, A. (2013). Effect of robot-child interactions on bilateral coordination skills of typically developing children and a child with autism spectrum disorder: A preliminary study. Journal of Motor Learning and Development, 1, 31-37.

Kim, E. S., Berkovits, L. D., Bernier, E. P., Leyzberg, D., Shic, F., Paul, R., et al. (2013). Social robots as embedded reinforcers of social behavior in children with autism. Journal of Autism and Developmental Disorders, 43(5), 1038-1049. doi:10.1007/ s10803-012-1645-2.

Kozima, H., Michalowski, M. P., \& Nakagawa, C. (2009). Keepon: A playful robot for research, therapy, and entertainment. 
International Journal of Social Robotics, 1, 3-18. doi:10.1007/ s12369-008-0009-8.

Kozima, H., Nakagawa, C., \& Yasuda, Y. (2007). Children-robot interaction: A pilot study in autism therapy. Progress in Brain Research, 164, 385-400. doi:10.1016/S0079-6123(07)64021-7.

Lee, H., \& Hyun, E. (2015). The intelligent robot contents for children with speech-language disorder. Educational Technology and Society, 18(3), 100-113.

Lee, J., Takehashi, H., Nagai, C., Obinata, G., \& Stefanov, D. (2012). Which robot features can stimulate better responses from children with autism in robot-assisted therapy? International Journal of Advanced Robotic Systems, 72(9), 1. doi:10.5772/51128.

McCleery, J. P. (2015). Comment on technology-based intervention research for individuals on the autism spectrum. Journal of Autism and Developmental Disorders, 45(12), 3832-3835. doi:10.1007/s10803-015-2627-y.

Mun, K. H., Kwon, J. Y., Lee, B. H., \& Jung, J. S. (2014). Design developing an early model of cat robot for the use of early treatment of children with autism spectrum disorder (ASD). International Journal of Control and Automation, 7(11), 59-74. doi:10.14257/ijca.2014.7.11.07.

Myers, S. M., \& Johnson, C. P. (2007). Management of children with autism spectrum disorders. Pediatrics, 120(5), 1162-1182. doi:10.1542/peds.2007-2362.

Neurodevelopmental Work Group. (2013). Autism spectrum disorder fact sheet. American Psychiatric Publishing. http://www.dsm5. org/Documents/Autism\%20Spectrum\%20Disorder\%20Fact\%20 Sheet.pdf.

Olds, J., Rubin, P., MacGregor, D., Madou, M., McLaughlin, A., Oliva, A., et al. (2013). Implications: Human cognition and communication and the emergence of the cognitive society. In M. C. Roco, W. S. Bainbridge, B. Tonn, \& G. Whitesides (Eds.), Convergence of knowledge, technology and society SE-6 (pp. 223-253). Berlin: Springer. doi:10.1007/978-3-319-02204-8_6.

Oros, M., Nikolic, M., Borovac, B., \& Jerkovic, I. (2014). Children's preference of appearance and parents' attitudes towards assistive robots. IEEE-RAS International Conference On Humanoid Robots, 360-365. doi:10.1109/HUMANOIDS.2014.7041385.

Pierno, A. C., Mari, M., Lusher, D., \& Castiello, U. (2008). Robotic movement elicits visuomotor priming in children with autism. Neuropsychologia, 46, 448-454. doi:10.1016/j.neuropsycholo gia.2007.08.020

Robins, B., \& Dautenhahn, K. (2014). Tactile interactions with a humanoid robot: Novel play scenario implementations with children with autism. International Journal of Social Robotics, 6(3), 397-415. doi:10.1007/s12369-014-0228-0.

Robins, B., Dautenhahn, K., Te Boekhorst, R., \& Billard, A. (2005). Robotic assistants in therapy and education of children with autism: Can a small humanoid robot help encourage social interaction skills? Universal Access in the Information Society, 4(2), 105-120. doi:10.1007/s10209-005-0116-3.

Robins, B., Dautenhahn, K., \& Dubowski, J. (2006). Does appearance matter in the interaction of children with autism with a humanoid robot? Interaction Studies, 7(3), 509-542. doi:10.1075/is.7.3. 16 rob.

Scassellati, B. (2005). Quantitative metrics of social response for autism diagnosis. Robot and Human Interactive Communication. ROMAN 2005. IEEE International Workshop on, 13-15 Aug 2005 (pp. 585-590). doi:10.1109/ROMAN.2005.1513843.

Scassellati, B., Admoni, H., \& Mataric, M. (2012). Robots for use in autism research. Annual Review of Biomedical Engineering, 14, 275-294. doi:10.1146/annurev-bioeng-071811-150036.
Schnelle, E. (1979). The Metaplan-method: Communication tools for planning and learning groups. Metaplan-GmbH: Publisher. ISBN 9783929147032.

Shamsuddin, S., Yussof, H., Hanapiah, F. A., Mohamed, S., Jamil, N. F. F., \& Yunus, F. W. (2015). Robot-Assisted learning for communication-care in autism intervention. In IEEE International conference on rehabilitation robotics (Vol. 2015, pp. 822-827). IEEE Computer Society.

Srinivasan, S. M., Lynch, K. A., Bubela, D. J., Gifford, T. D., \& Bhat, A. N. (2013). Effect of interactions between a child and a robot on the imitation and praxis performance of typically devloping children and a child with autism: A preliminary study. Perceptual and Motor Skills, 116(3), 885-904. doi:10.2466/15.10.PMS. 116.3.885-904.

Tapus, A., Peca, A., Aly, A., Pop, C., Jisa, L., Pintea, S., et al. (2012). Children with autism social engagement in interaction with Nao, an imitative robot-A series of single case experiments. Interaction Studies, 13, 315-347. doi:10.1075/is.13.3.01tap (Charman 1997)

Thill, S., Pop, C. A., Belpaeme, T., Ziemke, T., \& Vanderborght, B. (2013). Robot-assisted therapy for autism spectrum disorders with (partially) autonomous control: Challenges and outlook. Paladyn, 3(4), 209-217. doi:10.2478/s13230-013-0107-7.

Vanderborght, B., Simut, R., Saldien, J., Pop, C., Rusu, A. S., Pintea, S., et al. (2012). Using the social robot probo as a social story telling agent for children with ASD. Interaction Studies, 13(3), 348-372. doi:10.1075/is.13.3.02van.

Volkmar, F. R., Paul, R., \& Rogers, S. J. (2014). Handbook of autism and pervasive developmental disorders: Diagnosis, development, and brain mechanisms (Vol. 1). John Wiley \& Sons.

Wainer, J., Dautenhahn, K., Robins, B., \& Amirabdollahian, F. (2013). A pilot study with a novel setup for collaborative play of the humanoid robot KASPAR with children with autism. International Journal of Social Robotics, 6(1), 45-65. doi:10. 1007/s12369-013-0195-x.

Wainer, J., Robins, B., Amirabdollahian, F., \& Dautenhahn, K. (2014). Using the humanoid robot KASPAR to autonomously play triadic games and facilitate collaborative play among children with autism. Autonomous Mental Development, IEEE Transactions on, 6(3), 183-199. doi:10.1109/TAMD.2014. 2303116.

Warren, Z., Zheng, Z., Das, S., Young, E. M., Swanson, A., Weitlauf, A., et al. (2014). Brief report: Development of a robotic intervention platform for young children with ASD. Journal of Autism and Developmental Disorders. doi:10.1007/s10803-0142334-0.

Warren, Z. E., Zheng, Z., Swanson, A. R., Bekele, E., Zhang, L., Crittendon, J. A., et al. (2013). Can robotic interaction improve joint attention skills? Journal of Autism and Developmental Disorders. doi:10.1007/s10803-013-1918-4.

Wong, C., Odom, S. L., Hume, K., Cox, A. W., Fettig, A., Kucharczyk, S., et al. (2014). Evidence-based practices for children, youth, and young adults with autism spectrum disorder. Journal of Autism and Developmental Disorders. doi:10.1007/ s10803-014-2351-z.

World Health Organization. (2007). International classification of functioning, disability, and health: Children \& youth version: ICF-CY. Geneva: World Health Organization. ISBN 9241545429. 